\title{
Article \\ Impact of Rainfall-Induced Landslide Susceptibility Risk on Mountain Roadside in Northern Thailand
}

\author{
Chotirot Dechkamfoo ${ }^{1}$, Sitthikorn Sitthikankun ${ }^{2}$, Thidarat Kridakorn Na Ayutthaya ${ }^{2}$, Sattaya Manokeaw ${ }^{2}$, \\ Warut Timprae ${ }^{2}$, Sarote Tepweerakun ${ }^{2}$ D, Naruephorn Tengtrairat ${ }^{3}$, Chuchoke Aryupong ${ }^{1,4}$, \\ Peerapong Jitsangiam ${ }^{1,4}(\mathbb{D})$ and Damrongsak Rinchumphu ${ }^{1,4, * \mathbb{D}}$
}

1 Department of Civil Engineering, Faculty of Engineering, Chiang Mai University, Chiang Mai 50200, Thailand; chotirot_d@cmu.ac.th (C.D.); chuchoke.a@cmu.ac.th (C.A.); peerapong@eng.cmu.ac.th (P.J.)

2 City Research \& Development Center, Faculty of Engineering, Chiang Mai University, Chiang Mai 50200, Thailand; sitthikorn_si@cmu.ac.th (S.S.); thidarat_krid@cmu.ac.th (T.K.N.A.); sattaya_manok@cmu.ac.th (S.M.); warut_t@cmu.ac.th (W.T.); tarotrick@hotmail.com (S.T.)

3 School of Software Engineering, Payap University, Chiang Mai 50000, Thailand; naruephorn_t@payap.ac.th

4 Center of Excellence for Natural Disaster Management, Chiang Mai University, Chiang Mai 50200, Thailand

* Correspondence: damrongsak.r@cmu.ac.th

check for

updates

Citation: Dechkamfoo, C.; Sitthikankun, S.; Kridakorn $\mathrm{Na}$ Ayutthaya, T.; Manokeaw, S.; Timprae, W.; Tepweerakun, S.; Tengtrairat, N.; Aryupong, C.; Jitsangiam, P.; Rinchumphu, D. Impact of Rainfall-Induced Landslide Susceptibility Risk on Mountain Roadside in Northern Thailand. Infrastructures 2022, 7, 17.

https://doi.org/10.3390/ infrastructures7020017

Academic Editors: Sakdirat Kaewunruen, Erol Tutumluer and Alex M. Remennikov

Received: 18 December 2021

Accepted: 20 January 2022

Published: 26 January 2022

Publisher's Note: MDPI stays neutral with regard to jurisdictional claims in published maps and institutional affiliations.

Copyright: (C) 2022 by the authors. Licensee MDPI, Basel, Switzerland. This article is an open access article distributed under the terms and conditions of the Creative Commons Attribution (CC BY) license (https:// creativecommons.org/licenses/by/ $4.0 /)$.

\begin{abstract}
Landslide incidents frequently occur in the upper northern region of Thailand due to its topography, which is mostly mountainous with high slopes. In the past, when landslides happened in this area, they affected traffic accessibility for rescue and evacuation. For this reason, if the risk of landslides could be evaluated, it would help in the planning of preventive measures to mitigate the damage. This study was carried out to create and develop a risk estimation model using the artificial neural network (ANN) technique for landslides at the edge of the roadside, by collecting field data on past landslides in the study areas in Chiang Rai and Chiang Mai Provinces. A total of 9602 data points were collected. The variables for forecasting were: (1) land cover, (2) physiographic features, (3) slope angle, and (4) five-day cumulative rainfall. Two hidden layers were used to create the model. The number of nodes in the first and second hidden layers were five and one, respectively, which were derived from a total of 25 trials, and the highest accuracy achieved was $96.74 \%$. When applying the model, a graph demonstrating the relationship between the landslide risk, rainfall, and the slopes of the road areas was obtained. The results show that high slopes result in more landslides than low slopes, and that rainfall is a major trigger for landslides on roads. The outcomes of the study could be used to create risk maps and provide information for developing warnings for high-slope mountain roads in the upper northern region of Thailand.
\end{abstract}

Keywords: landslide; rainfall-induced; artificial neural network; mountain roadside; northern Thailand

\section{Introduction}

Natural disasters are becoming more severe and occur more frequently, causing inevitable damage and impacting people. Landslides are an interesting type of disaster that should be of concern for study as they are the seventh most severe natural disaster among all natural disasters [1] and can cause catastrophic losses and death [2]. They mostly occur in the mountains on steep slopes that lack internal balance and on hillsides that lack tree cover, which helps to absorb water. When it rains in an area until the land cover is saturated and unable to absorb any more water, land collapses down the slope due to gravity. Rainfall is considered a significant trigger of landslides in many parts of the world. Abraham et al. [3] stated that rainfall is a main factor causing landslides in most elevated areas in India. In addition, in Thailand, rainfall and landslides are clearly and significantly related. The study of landslide risk assessment by Petpongpan et al. [4] also showed that rainwater is the main cause of landslides. Regarding landslides in Thailand, it is known 
that landslides occur frequently in the upper northern region of Thailand because the topography of the area is flat terrain alternating with mountainous areas with high slopes, which are mostly part of the mountainous terrain [5], as shown in Figure 1, which gives an example of the topography of Chiang Rai Province, a province in the upper northern part of Thailand.

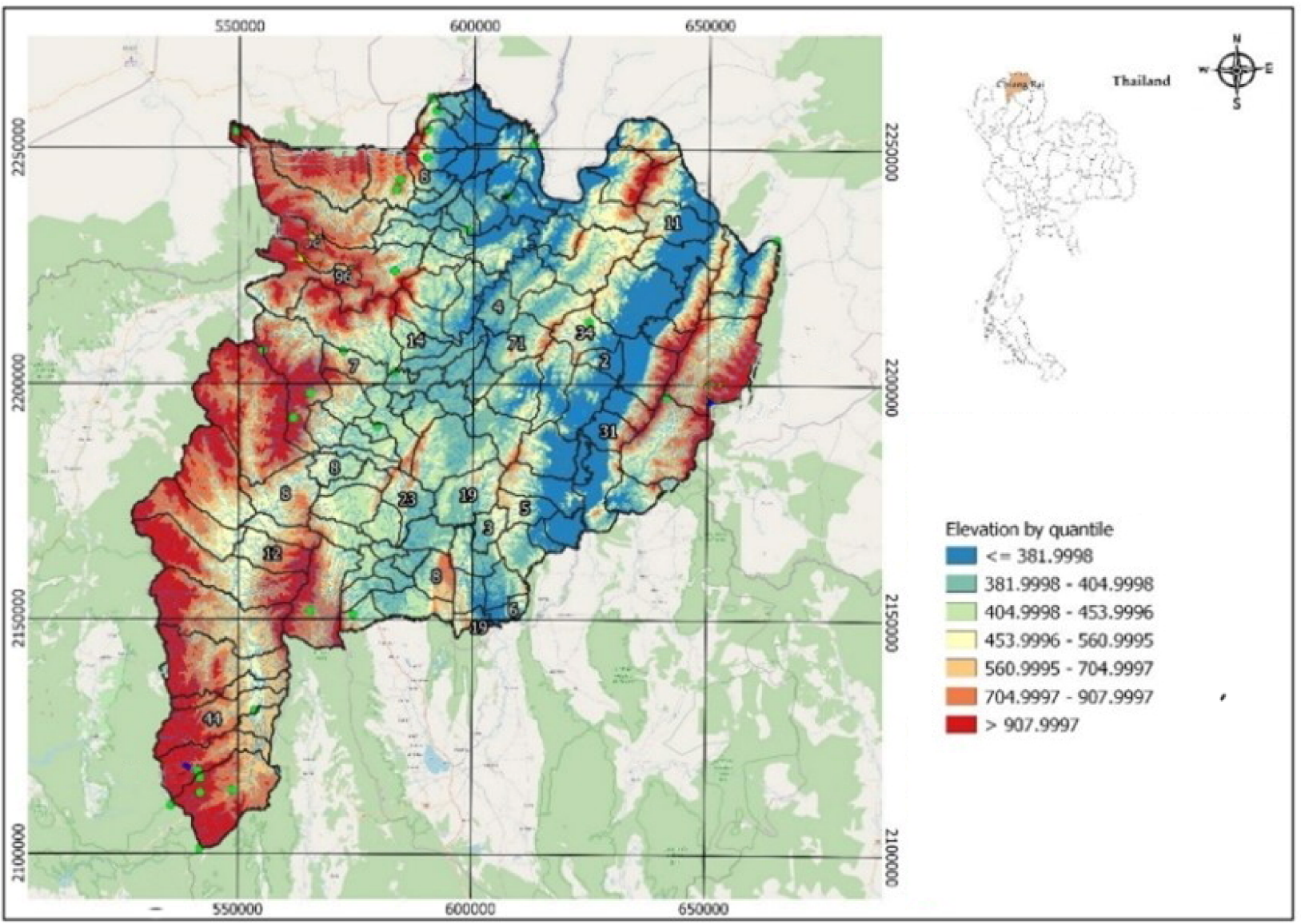

Figure 1. Topography of Chiang Rai Province, a province in the upper north of Thailand, adapted with permission from ref. [6].

Based on past incidents, landslides are frequently found at the edges of roads, and examples of damage overviews can be found in the news. For example, in August 2019, a landslide covered a route leading to tourist attractions in the north of Thailand [7], and in August 2021, a landslide caused a large rock to block a road [8]. These incidents show that landslides at the edges of roads affect traffic and result in a loss of communication between communities. Sometimes, there is also damage to roadside structures, as shown in Figure 2.

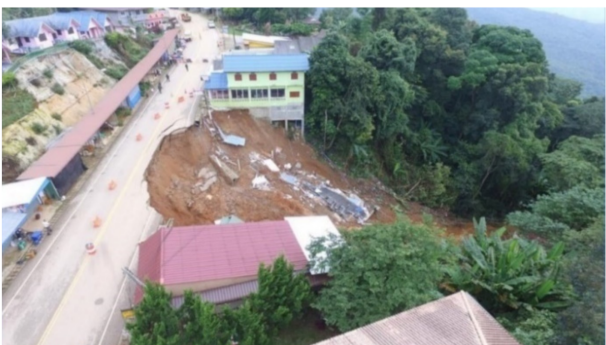

(a)

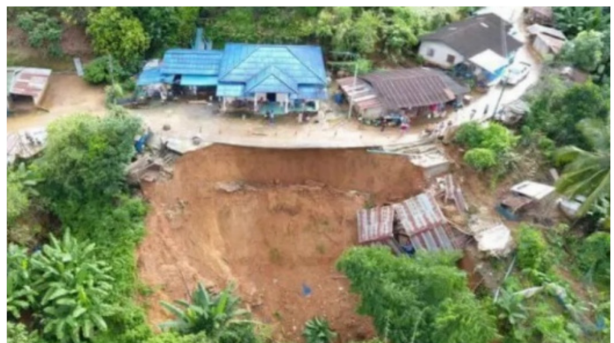

(b)

Figure 2. Examples of landslides in Chiang Rai Province. (a) Phu Chifa, Tambon Tap Tao, adapted with permission from ref. [9], (b) Ban Pha Dua, Tambon Mae Salong Nai, adapted with permission from ref. [10]. 
Therefore, to reduce the impact of landslides and the damage they cause, it is important to estimate the risk of landslides before they occur, as this can help in surveillance and the planning of prevention measures to avoid damage from future landslides. Although modeling methods have been studied to forecast landslides in various areas, to the best of our knowledge there has been no research related to landslide susceptibility risk modeling in northern Thailand, which has unique characteristics. Moreover, this study offers a scientific contribution in presenting a model for applying a data analysis approach instead of heuristic analysis, in order to reduce the data collection time and benefit other researchers. However, there are factors that affect the landslide when a landslide does occur, and these will be discussed in the next section. The rest of the paper is structured as follows: Section 2 describes the factors that affect the landslide risk; Section 3 presents modeling techniques; the methodology is presented in Section 4; Section 5 presents the results; and Section 6 includes a discussion and conclusions.

\section{Factors That Impact Landslide Risk}

In general, landslides can occur in a variety of ways, and there are many factors that cause landslides, such as type of land cover, physiographic classifications, slope angle, and rainfall. However, when reviewing the literature on factors related to landslides, it was identified that the factors that were relevant to this study included the following.

\subsection{Type of Land Cover}

Landslides are caused by the movement of the topsoil, so an important factor in landslides is the binding capacity of the topsoil of the land cover. Due to changes in soil conditions, from natural forest to agriculture, road construction, or buildings, similar areas have different land cover. In past research, land cover has been considered important. According to Shu et al. [11] and Tengtrairat et al. [6], land cover is divided into five types, whereas Zhao et al. [12] categorized land cover into six types. Most researchers will choose to use a classification approach that is in accordance with the conditions of the study area. In this study we categorize five types of land cover: (1) bare soil, (2) buildings, (3) roads, (4) grass, and (5) trees. In conclusion, land cover is an indispensable factor associated with the occurrence of landslides in the considered area.

\subsection{Physiographic Classifications}

Generally, landslides are caused by physiographic weathering of different rock types, in which the weathering rate of each type is dissimilar. When a rock layer decays, it becomes soil. The unequal decay rates of rocks will result in different adhesion properties between the soil granules and different soil erosion resistance values. In addition, faults and the orientation of the rock layers also affect weathering [13]. Most of this is due to the structure of rock layers and the effects of weather conditions, making them prone to landslides [14]. Physiographic classifications are divided by area. Marc et al. [15] divided rocks into four types, whereas Chen et al. [16] categorized them into three main types. Therefore, physiographic classifications usually depend on information about the studied areas. According to the Department of Mineral Resources, Thailand [5], the physiographic properties in the upper northern region of Thailand are divided into two types: (1) sedimentary or metamorphic rock and (2) igneous rock. When compiled with the previous literature, these two rock types can be used as important variables in risk assessment modeling in the upper northern region of Thailand.

\subsection{Slope Angle}

Slope is an influencing variable and is often used as a variable for landslide analysis because landslides are associated with higher slopes. Therefore, areas with high slopes are prone to landslides [17]. A high slope tends to cause the soil to lose stability and move down the slope of the mountain, and thus the area is more prone to landslides than low-slope areas. Landslides can occur at slopes in the range of $15^{\circ}-30^{\circ}$, and the highest landslide 
tendencies are in slopes of $25^{\circ}-30^{\circ}$ [18], although some studies have concluded that most landslides occur on slopes of $30^{\circ}-40^{\circ}$ [19]. This is due to consideration of other factors affecting landslides in the area. However, the main conclusions from the analysis of the landslide mechanism by Zhongping et al. [20] is that the slope areas under consideration should be in the range of $10^{\circ}-30^{\circ}$. Therefore, the slope factors of the area directly affect the occurrence of landslides in high slope areas in upper northern Thailand.

\subsection{Amount of Rainfall}

This is a variable that increases the weight of the soil mass relative to normal conditions and reduces the amount of movement resistance. Most landslides are caused by extended heavy rainfall on mountain slopes, causing the wet soil layer to be unable to absorb more water, resulting in slides and collapse [13]. Most landslides are triggered by rainfall [21], which is the primary direct factor in determining landslides. Areas with heavy rainfall are likely to develop landslides [22]. The occurrence of landslides is caused by cumulative rainfall of more than three days [23]. Due to the infiltration of rainwater, slope instability is observed for unsaturated soils [24]. Therefore, it is generally known that the amount of rainfall definitely affects landslides. The rainfall data used must be from reliable and usable sources such as the Department of Water Resources or others that collect daily rainfall data from the monitoring stations which have been systematically distributed throughout the region for many years. To apply rainfall data, if the area under consideration is large, an area distribution analysis is used to calculate the average rainfall over the area, which is determined by averaging using the isohyetal method.

Regarding the review of the literature, it can be concluded that the factors mentioned above, including the type of land cover, physiographic classifications, slope angles, and amount of rainfall, are all important in the occurrence of landslides. Now that the factors contributing to landslides have been identified, the next step is to apply these factors to forecasting the risk of landslides. However, forecasting modeling requires a variety of modern techniques, with a preference for popular and literature-reviewed techniques for accuracy, to create a model to estimate the risk of occurrence, which will be discussed in the next section.

\section{Modeling Techniques}

Nowadays, the use of modern techniques to assist with modeling in various fields has begun to play an increasingly important role. There are a variety of techniques for modeling landslide forecasting. We found a total of 13 articles detailing forecasting techniques from 2019 to 2021, and the types and number of techniques used are summarized in Figure 3.

Some of the articles in Figure 3 used more than one technique. In landslide forecasting modeling, each of the techniques has different strengths. ANN was the most commonly used technique [25-35], followed by logistic regression [28,29,33-36]. Next, were support vector machine, naive Bayes, and random forest, each of which were used twice [28,33,35-37]. Lastly, kernel logistic regression was used once [37].

The artificial neural network (ANN) technique is well accepted in landslide forecasting modeling because of its high efficiency and accuracy. It is a mathematical or computational modeling technique for processing information with the use of connections by studying neurons and synapses. The idea is that computers are capable of learning like humans, so they can be trained and taught to apply information to forecasting. The standard structure of ANNs is divided into three main parts: an input layer, hidden layers, and an output layer, which are all essential for the ANN modeling processes; the number of hidden layers must be determined and tested in order to achieve the best forecasting results. An example of an ANN is shown in Figure 4. 


\section{Support Vector Machine}

\section{Artificial Neural Networks}

Kernel Logistic Regression

Naive Bayes

Logistic Regression

Random Forest
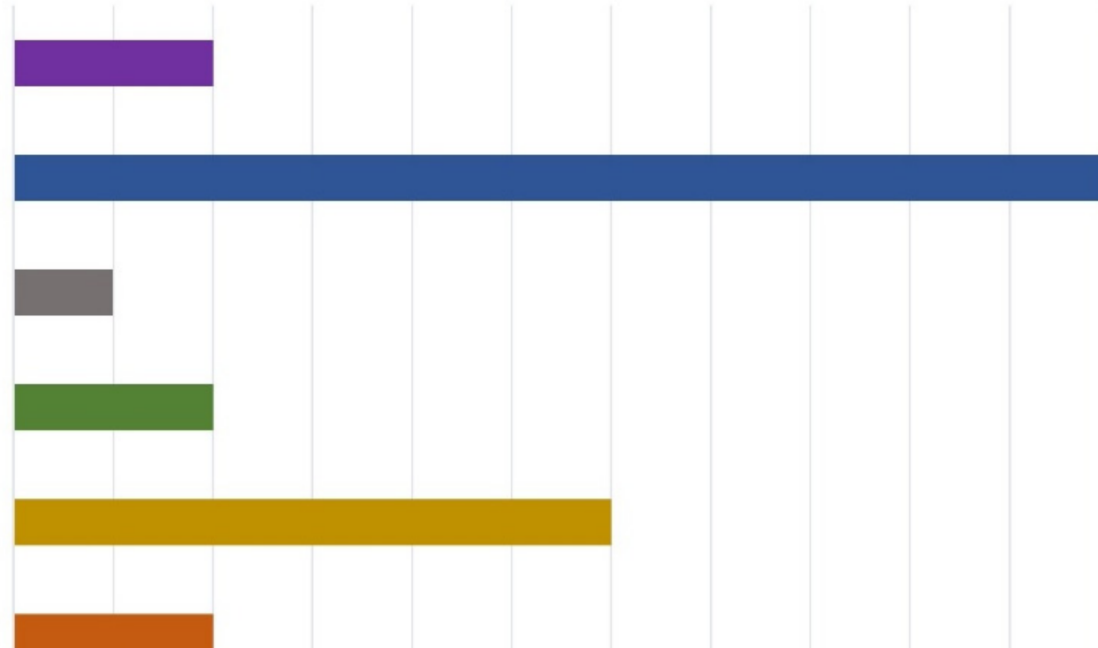

0

123

4

$5 \quad 6$

7

8

$9 \quad 10$

Figure 3. Number of applied forecasting techniques from literature.

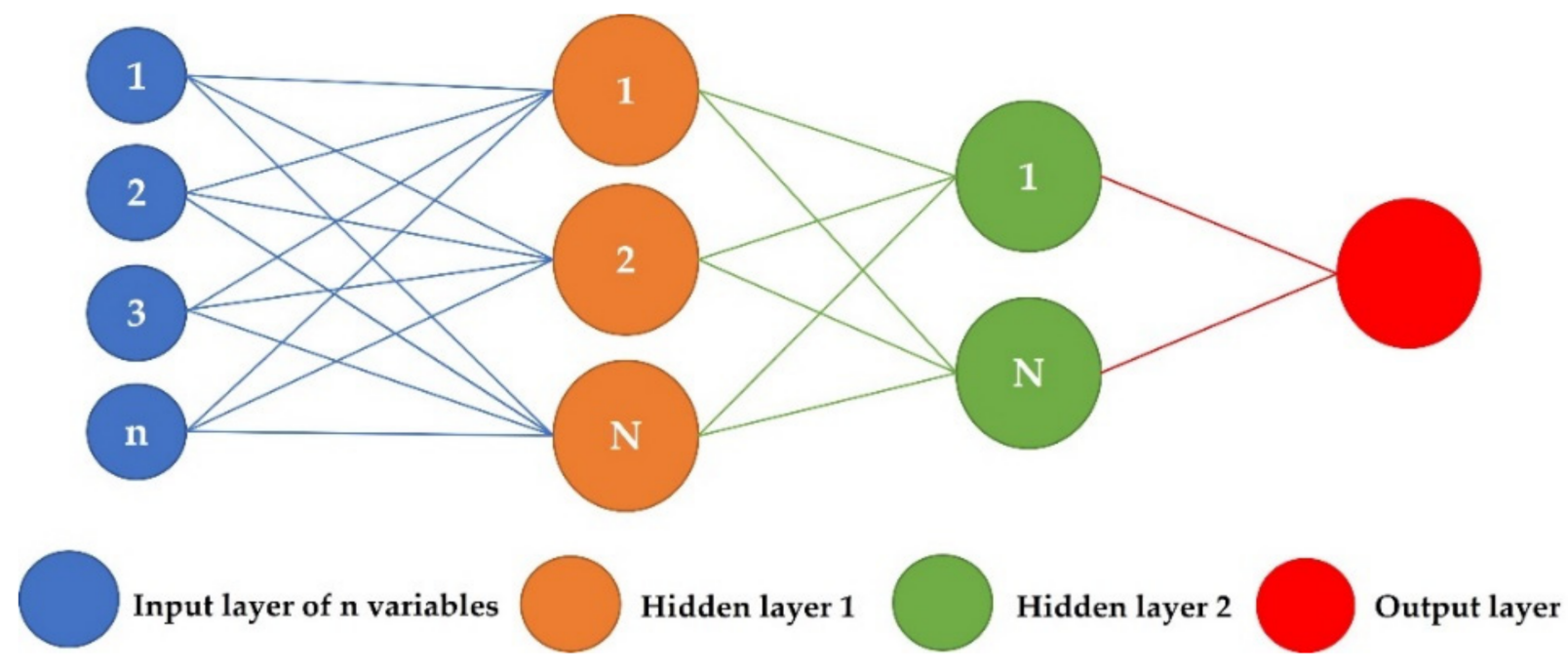

Figure 4. Artificial neural network (ANN) architecture.

Nowadays, there are a number of software programs that support non-coding for predictive events using ANN modeling, which are useful to members of the general public who are not proficient in coding and can be applied to the data analysis approach. One of those programs is RapidMiner [38,39]. RapidMiner is a free-to-use program with a few limitations, but its basic functions can be used to create forecasting models. Sitthikankun et al. [40] used this program to estimate construction costs using an ANN, and Celik and Basarir [41] applied an ANN to forecast metal prices, using RapidMiner to create forecast models. The users referred to are non-coding professionals who used RapidMiner to create forecasting models without having to write the code themselves, with little understanding of the basics of source-code writing. This is known as no-code platform development. The methodology will be discussed in the next section.

\section{Methodology}

The stepwise methodology is shown in Figure 5. 


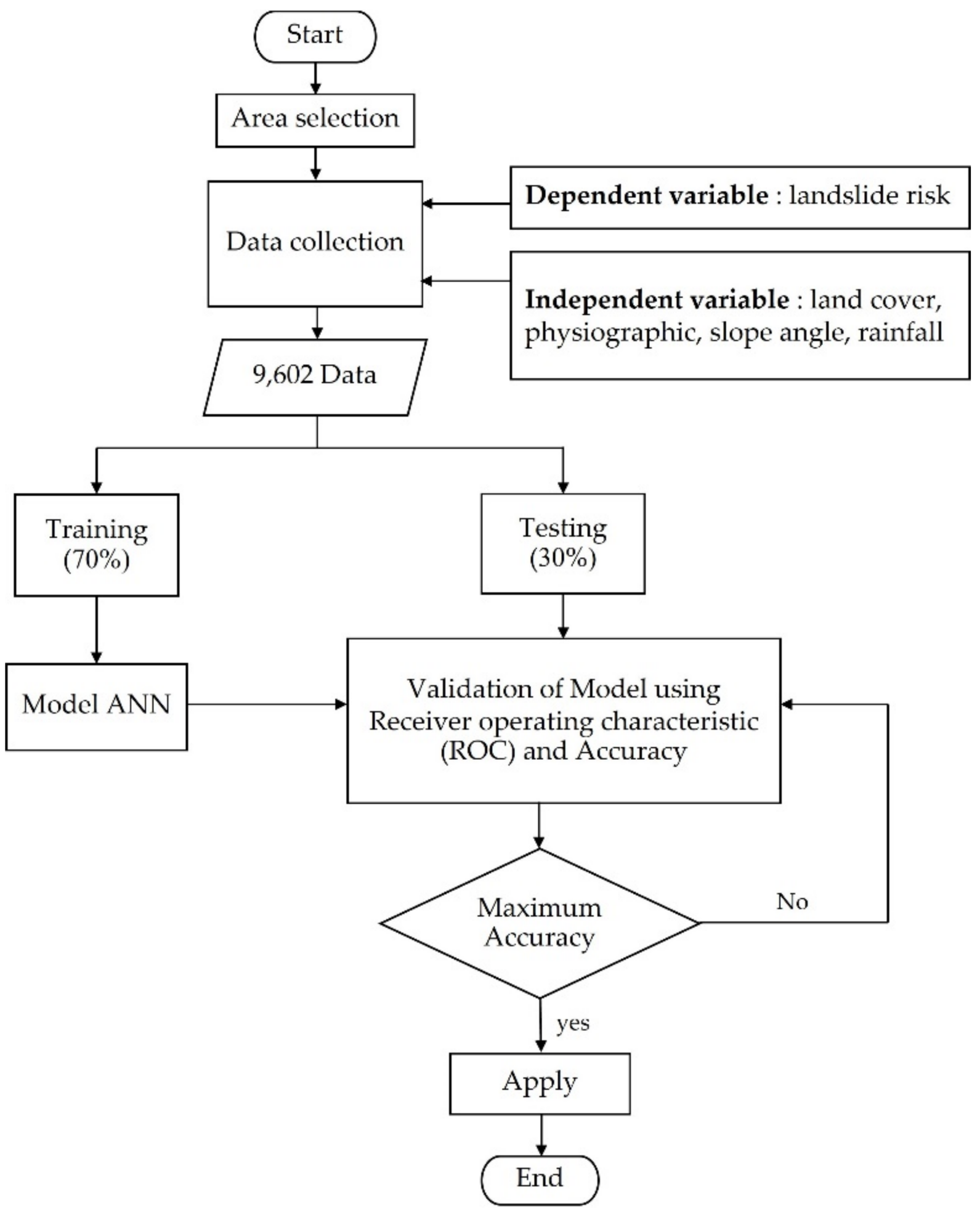

Figure 5. Methodology.

The methodology shown in Figure 5 is divided into 3 main processes: first, the data collection process, which is described in detail in Sections 4.1 and 4.2; second, the modeling process for data forecasting, which is be described in detail in Section 4.3; and third, the model accuracy testing process that consists of the results of the experiment, the details of which are presented below. 


\subsection{Area Selection}

Considering a study area in the upper northern region of Thailand, areas located on steep slopes that were prone to landslides were selected. Initially, Chiang Rai and Chiang Mai Provinces were selected because there have been landslides on roadsides at many points that have caused losses to the communities and affected traffic on tourist routes. Examples of traces of landslides in Chiang Rai and Chiang Mai are shown in Figure 6.

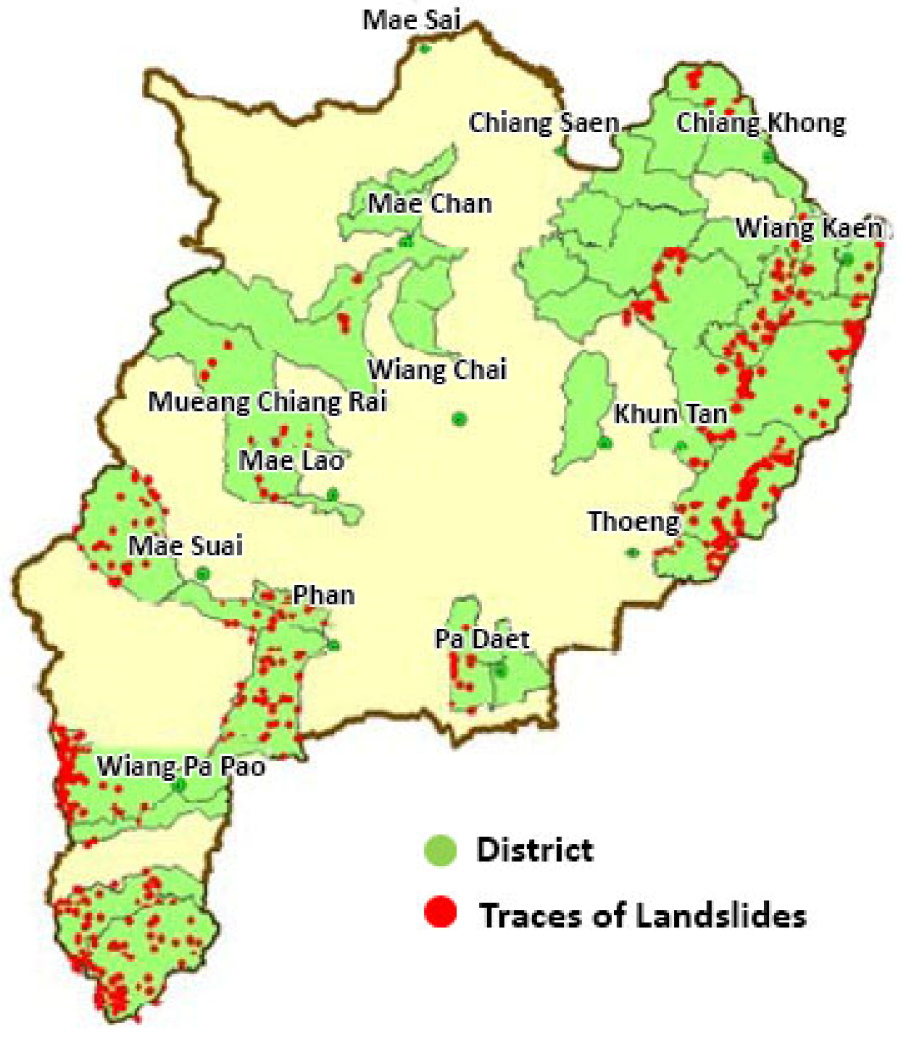

(a)

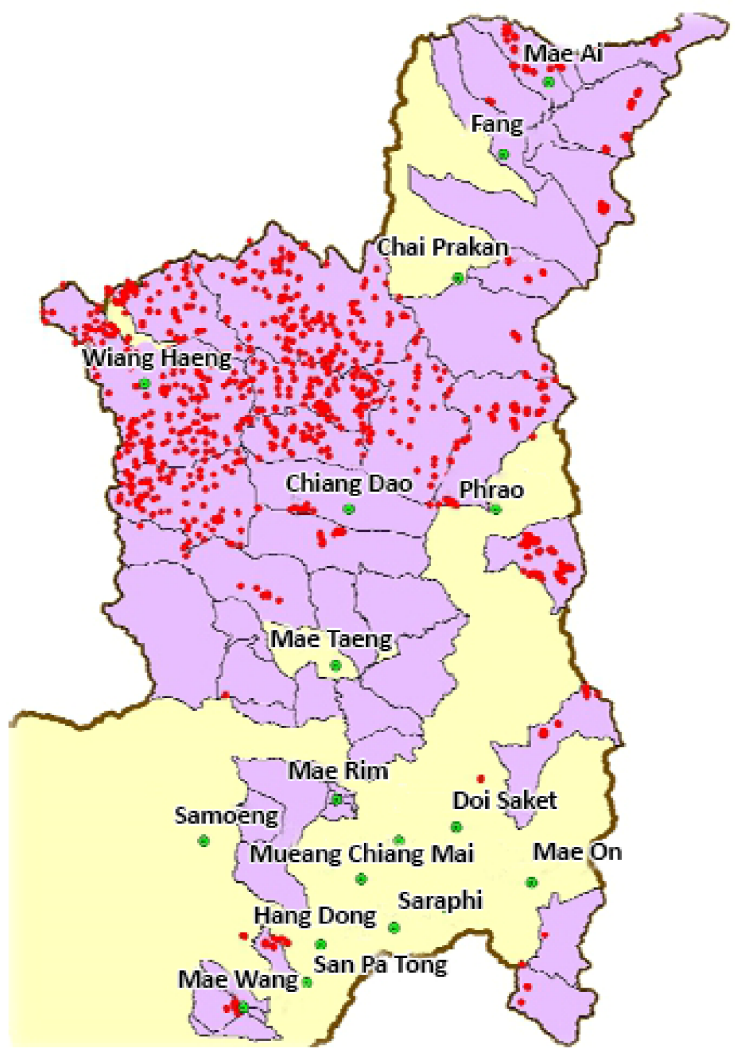

(b)

Figure 6. Traces of past landslides in the study areas. (a) Chiang Rai Province area, adapted with permission from ref. [42], (b) Chiang Mai Province area, adapted with permission from ref. [43].

\subsection{Data Collection}

To develop a forecasting model for landslide risk using an ANN, we used a data analysis approach based on finding the relationship between the source variables and the dependent variables by using incidents or occurrence data of landslides collected in the past. The dependent variable data refer to the level of landslide risk. The independent variables were the variables affecting the change in the likelihood of risk, including land cover, physiographic classifications, slope angles, and the amount of rainfall. First, we collected data from landslides in the study areas in Chiang Rai and Chiang Mai Provinces, which are provinces in the upper north of Thailand where frequent landslides occur. We collected data from 12 past landslide events from 7 areas and their surroundings, as listed in Table 1 below; the imported datasets were used to generate a $5 \times 5 \mathrm{~m}$ grid from both the area where the landslide occurred and the surrounding area. The area where the landslide occurred was assigned the risk number 1 , and the surrounding area was assigned the risk number 0 .

Based on the incidents listed in Table 1, data collection of key variables was carried out; each variable had to be updated before being used to create a landslide risk forecasting model, which is described in the following. All of the data collection process are explained in Figure 7. 
Table 1. Locations and dates of landslides in the study areas.

\begin{tabular}{clc}
\hline Province & \multicolumn{1}{c}{ Area } & \multicolumn{1}{c}{ Date } \\
\hline \multirow{3}{*}{ Chiang Rai } & $\begin{array}{l}\text { 1. Phu Chifa, Tambon Tap Tao, Thoeng District } \\
\text { 2. Santikhiri Village, Tambon Mae Salong Nok, } \\
\text { Mae Fa Luang District }\end{array}$ & 31 July 2018 \\
& $\begin{array}{l}\text { 3. Sop Ruak Village, Tambon Wiang, Chiang } \\
\text { Saen District }\end{array}$ & 12 July 2013 \\
\hline & 4. Tambon Mon Pin, Fang District & \\
\hline Chiang Mai & 5. Tambon Huai Kaeo, Mae On District & 21 September 2020 \\
& 6. Tambon Suthep, Muang Chiang Mai & 21 August 2020 \\
& 7. Tambon Ban Luang, Chom Thong District & 23 August 2020 \\
\end{tabular}

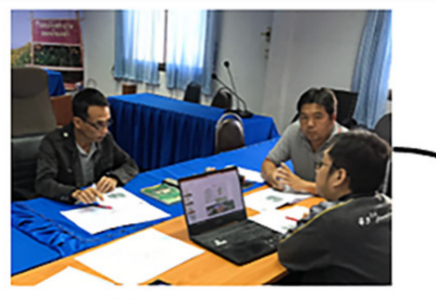

(a) Site survey

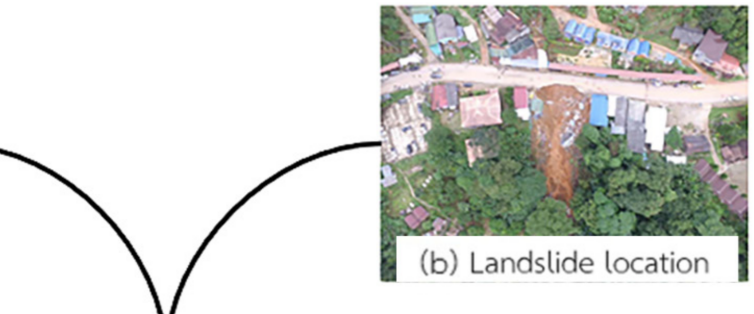

(c) Land cover

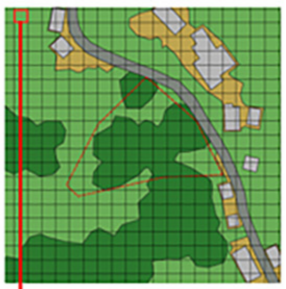

(d) Physiographic

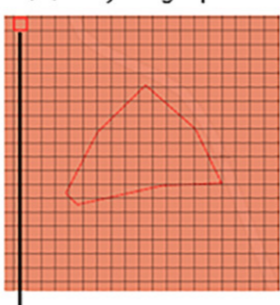

Data digitization to $5 \times 5 \mathrm{~m}$. grid in

GIS-shape file format

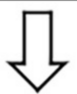

(e) Slope angle

(f) Five-day cumulative

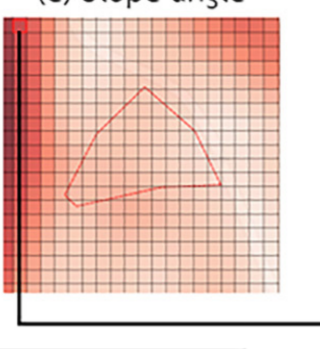

rainfall

(g) Landslide

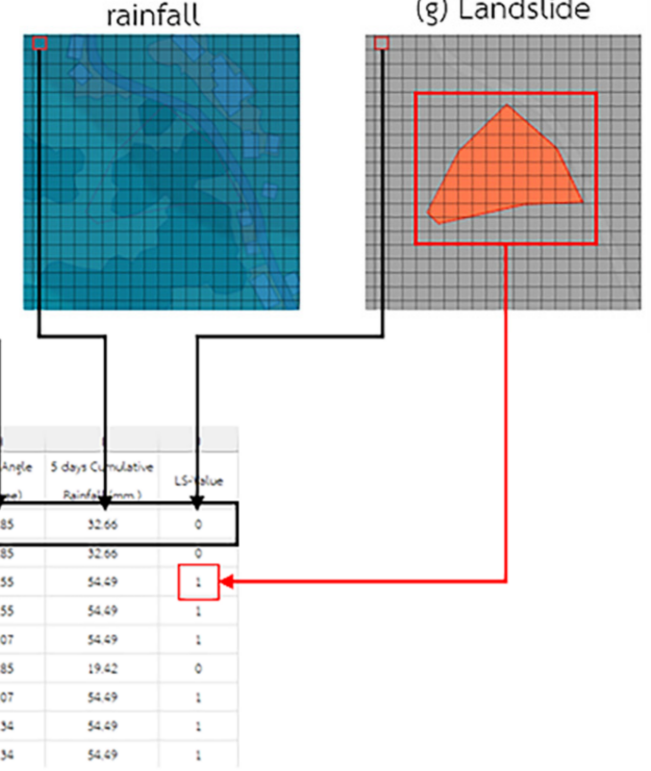

Figure 7. Diagram of data collection process.

The data collection process is summarized in Figure 7. In accordance with the data in Table 1, the next step was to conduct a site survey to gather further information about the landslide event, including requesting information from government entities in the area about previous accidents, as indicated in Figure 7a,b. Then, using numerous data digitization processes from the original format to a GIS shapefile format, all data, including land cover, physiographic classifications, slope angles, and five-day cumulative rainfall data, were sourced from credible secondary data sources. 
The land cover digitization of data was achieved by importing aerial images from Sentinel-2 satellites into the Quantum Geographic Information System (QGIS) program and classifying the land cover using the Semi-Automatic Classification Plugin command in QGIS. The land cover was divided into five sub-categories, as follows. (1) Bare Soil: this is bare soil with nothing covering it; the soil surface can directly receive rainwater. (2) Building: this data represents the hardscape areas (excluding roads), such as buildings, parking lots, stadiums, and so on. (3) Grass: an area covered with small, low-growing plants, the majority of which are herbaceous plants or shrubs. (4) Road: road profiles are separated from buildings and covered with asphalt, which has a very low water seepage rate. (5) Tall trees: in this area, large trees cover the soil. The majority of them are perennials that can reach heights of more than $5 \mathrm{~m}$. Figure $7 \mathrm{c}$ depicts all of these land cover data. In terms of physiographic classification, there are two types of rocks: igneous or sedimentary rock and metamorphic rock. These data were obtained from the Department of Mineral Resources and were already in digital format (GIS shapefile) and ready for use in the next step. Slope angle data were obtained by importing the ALOS PALSAR satellite's Digital Elevation Model (DEM) files into the calculation process via the Slope command in the QGIS program. Meanwhile, cumulative rainfall data from rain-gauge stations near the incident site were used to generate isohyet data for the study area. Interviews with responsible local people were conducted at each site to collect 5 days of cumulative rainfall data prior to the day of the landslide. Figure $7 \mathrm{~d}-\mathrm{f}$ shows the physiographic classifications, slope angles, and 5-days cumulative rainfall data digitized in the QGIS step, respectively. The incident site was surveyed to find any traces of landslides that remained from the previous, and digitization techniques were used to convert raw data into GIS shapefiles for landslide/non-landslide points. Figure 7 depicts a landslide point with a value of 1 and adjacent points with values of 0 (g).

The final step was to overlay all the GIS shapefile data with a $5 \mathrm{~m}$ grid and save all the data mentioned above into each grid, with outliers removed, until there were 9602 usable data left. As shown in Figure 7h, these data were sent to a Microsoft Excel spreadsheet in preparation for the next step.

\subsubsection{Landslide Risk}

The physical data on past landslide areas from the study areas were obtained by examining the landslide characteristics, the duration of occurrence, the damaged areas, and the weathering characteristics, along with collecting recorded local damage photos and news articles, to convert them into datasets for modeling. If a location had never had a landslide, the value was 0 , and the value was 1 if a landslide had occurred before.

\subsubsection{Land Cover}

Field visits were conducted to survey and collect physical data, which were used together with aerial photographs. The aerial photographs had to be converted into digital files, and the land cover type data were imported from the Quantum Geographic Information System (QGIS) program using the Semi-Automatic Classification Plugin, to classify the land cover into five groups, as illustrated in Figure 8.

\subsubsection{Physiographic Classifications}

Field visits were undertaken to survey locations, and a physiographic dataset from the Department of Mineral Resources was used [13]. Using digital files displayed through the QGIS program, a map was made illustrating the properties of the rock layers in the study area, and the result is shown in Figure 9. 

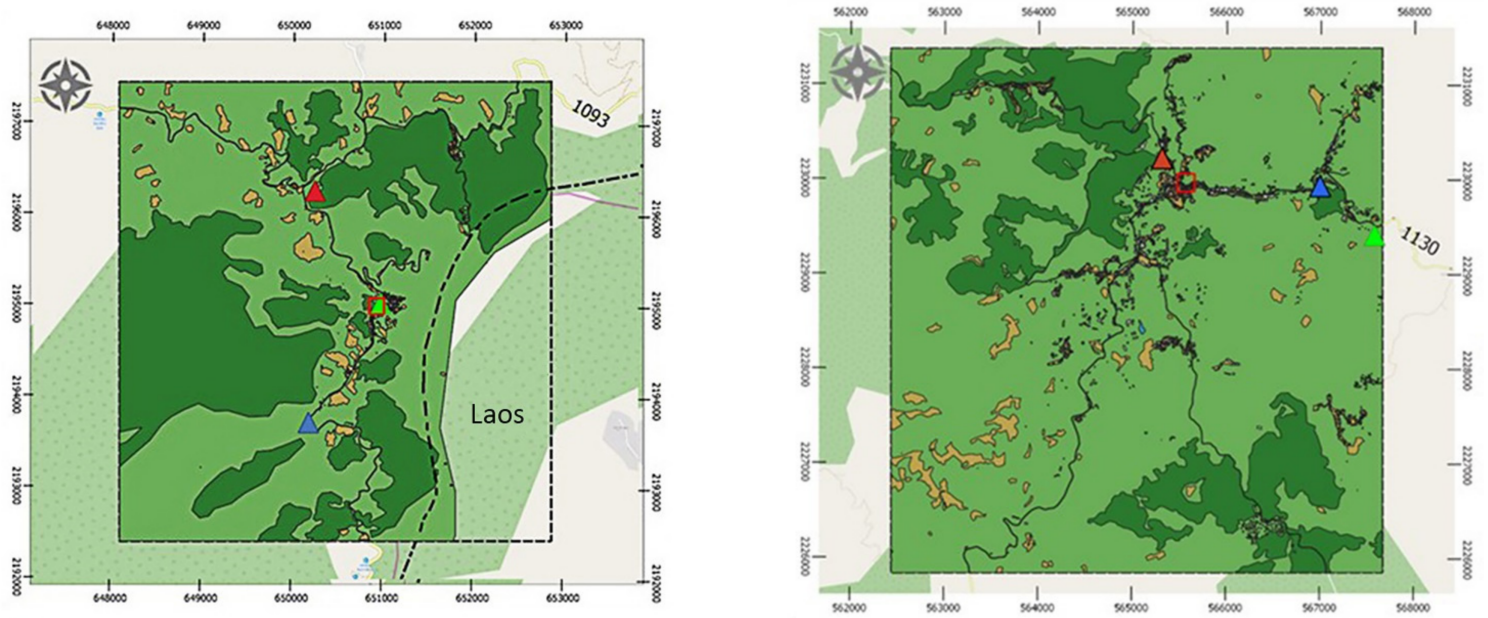

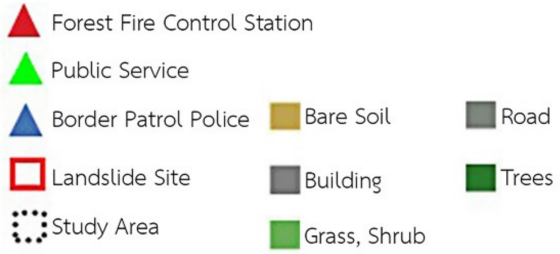

(a)
Temple

$\Delta$ Subdistrict Administrative Organization

\begin{tabular}{|c|c|}
\hline$\Delta$ school & Bare Soil \\
\hline$\square$ Landslide Site & $\square$ Building \\
\hline :...:Study Area & Grass, Shrub \\
\hline
\end{tabular}

(b)

Figure 8. Examples of land cover of study areas retrieved from QGIS. (a) Tambon Tap Tao, Thoeng District, (b) Tambon Mae Salong Nok, Mae Fa Luang District.

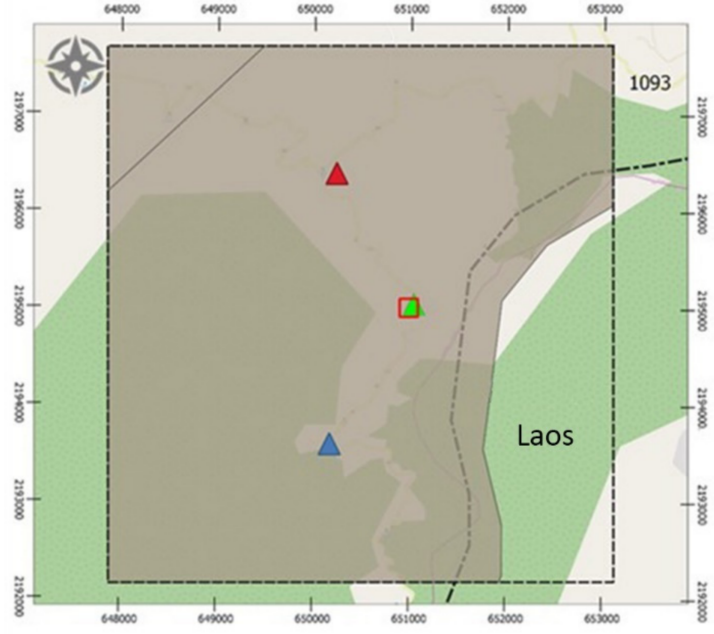
Forest fire Control
Station
Public Service
Border Patrol
$\square$ Landslide Site
:...:Study Area

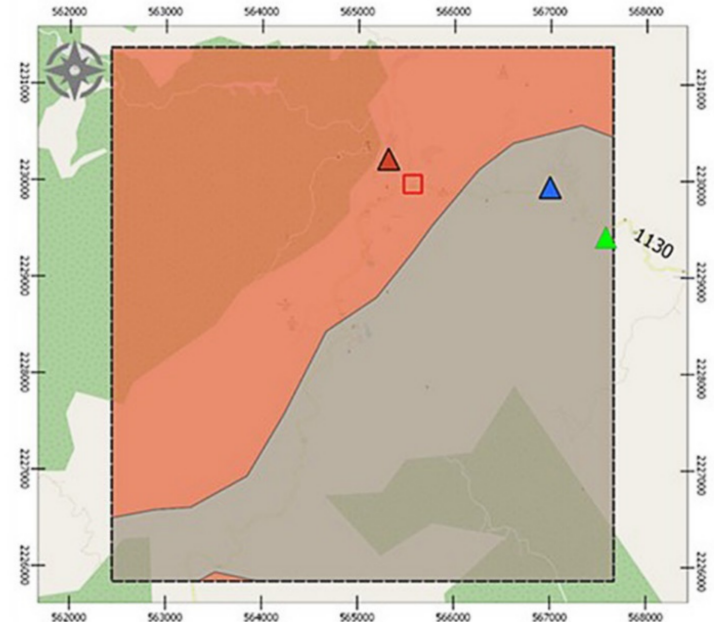
Subdistrict Administrative
Organization Igneous Rock
A School Sedimentary Rock,
Aemple Metamorphic Rock
$\square$ Landslide Site
$\because .$. Study Area

Figure 9. Examples of physiographic maps retrieved from QGIS. (a) Tambon Tap Tao, Thoeng District, (b) Tambon Mae Salong Nok, Mae Fa Luang District. 


\subsubsection{Slope Angle}

Field visits and data collected by searching maps from the Department of Mineral Resources were used to create slope maps for the study areas, and the results were displayed through the QGIS program. Examples are illustrated in Figure 10.

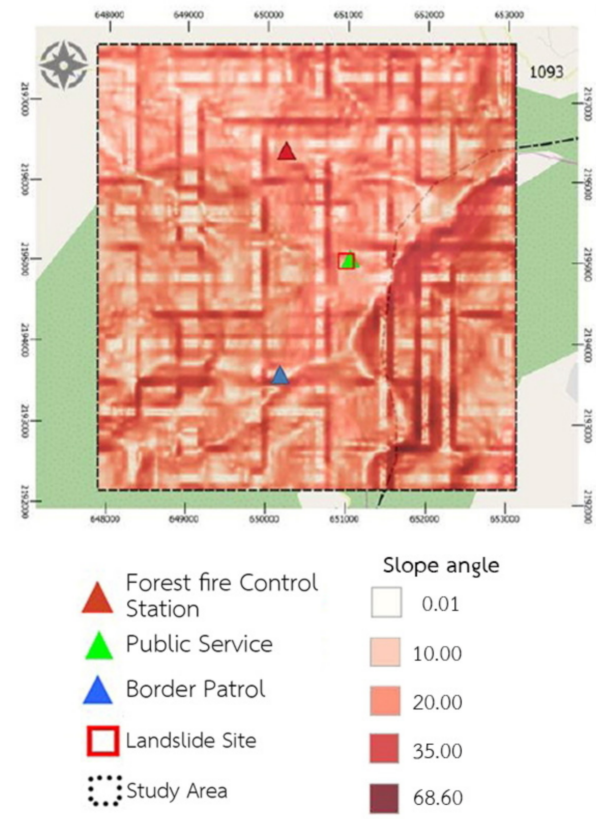

(a)

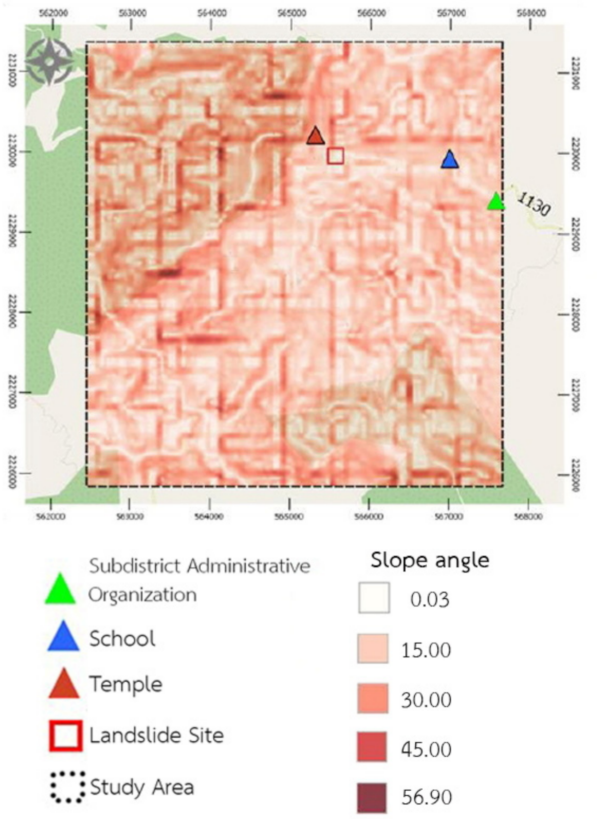

(b)

Figure 10. Examples of slope angle maps retrieved from QGIS. (a) Tambon Tap Tao, Thoeng District, (b) Tambon Mae Salong Nok, Mae Fa Luang District.

\subsubsection{Rainfall}

We selected the rainfall values from the Department of Water Resources rain-gauge stations located in the vicinity of the study areas. Rainfall data were collected for the five days before the landslides at each station near the study areas by creating isohyets, and the results were visualized through the QGIS program before they were extracted to create a model. An example of the vicinity of a rainwater station selection is shown in Figure 11.

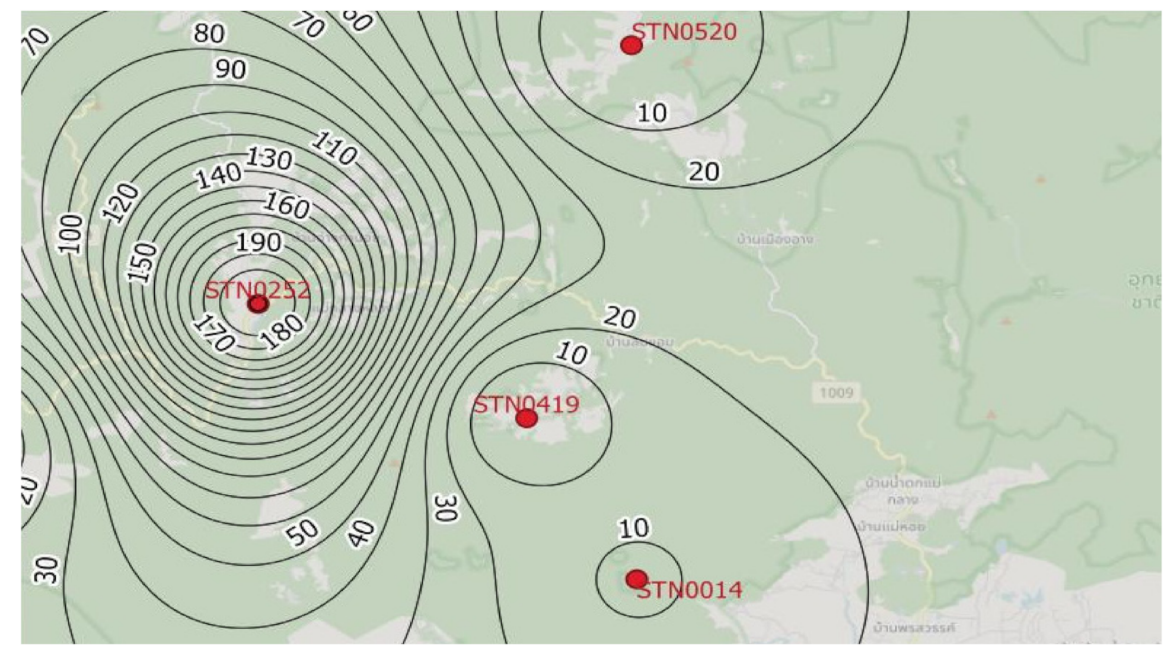

Figure 11. Example of isohyets from the vicinity of rainfall station in Chiang Mai.

Following the data collection for modeling, the imported datasets were generated from the study area maps in a $5 \times 5 \mathrm{~m}$ grid format by extracting the data from QGIS. A total of 9602 data points were selected and collected from areas in Chiang Rai and Chiang 
Mai Provinces, consisting of landslide risk, land cover, physiographic classifications, slope angles, and five-day cumulative rainfall. A breakdown of the data is presented in Figure 12.

(a)
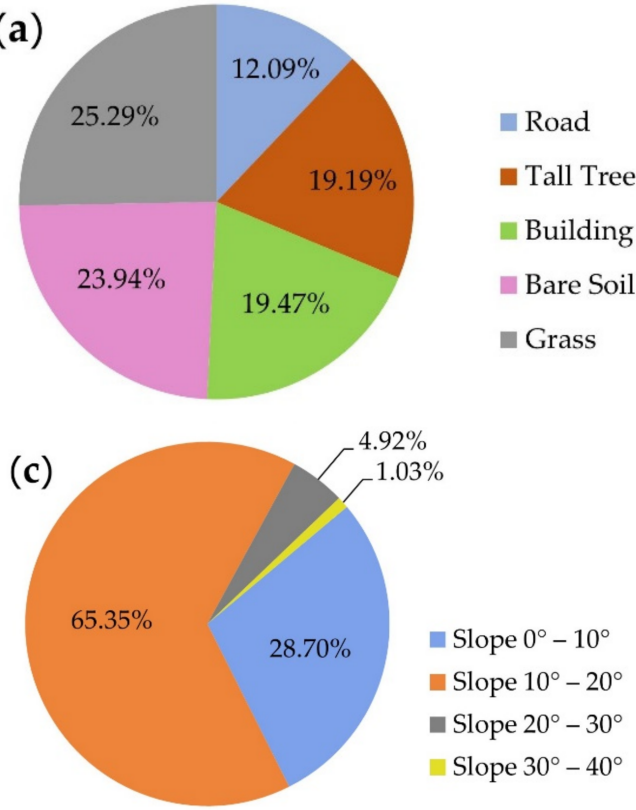

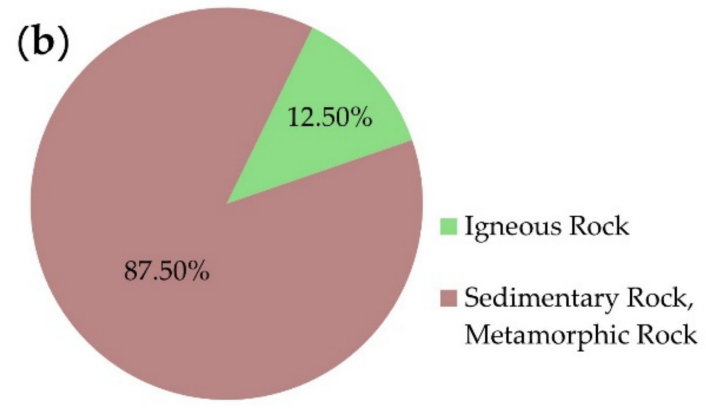

(d)

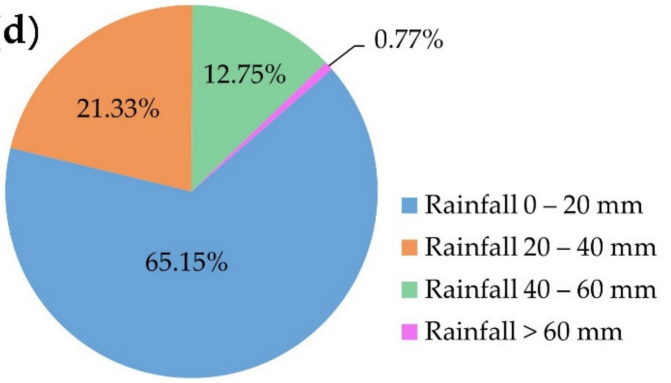

Figure 12. Breakdown of study of: (a) land cover; (b) physiographic classifications; (c) slope angle; (d) five-day cumulative rainfall.

As seen in Figure 12, the following can be observed regarding the four types of information collected. (1) In land cover, grass had the highest proportion, followed by bare soil, while road area was the smallest. This is because this study area is located in rural areas, where built areas are normally smaller than natural areas. (2) Metamorphic and sedimentary rocks were more common than igneous rocks. (3) The majority of the slope angle data in each grid had values less than $20^{\circ}$, because community areas tend to be located in areas with no steep slopes, whereas the previous landslide locations were usually located in areas with slopes steeper than $20^{\circ}$. (4) The five-day cumulative rainfall data had values of less than $20 \mathrm{~mm}$ in more than half of the grid. However, due to the data collected being surrounding-area data, the data included low rainfall areas; the cumulative precipitation at the accident sites was higher than $60 \mathrm{~mm}$, and thus, this information is reasonable.

\subsection{Forecasting Modeling via RapidMiner}

In the forecasting modeling, various functions within RapidMiner were used to create the modeling processes to forecast landslide risk with an ANN. The processes created are shown in Figure 13.

According to the processes of the modeling, in the neural net function part, the number of nodes for each layer in the hidden layers must be determined. This is considered an important step in the conventional feedforward ANN model. However, there is still doubt regarding how many hidden layers are needed. This decision is based on general rules (rules of thumb) in ANN modeling. Ranjan [44] stated that the number of hidden layers should be approximately two, with the first hidden layer having approximately half the number of independent variables, and the next hidden layer having half the number of nodes as the first hidden layer. Nevertheless, other node amounts should not be ignored. Sitthikankun et al. [40] performed trial-and-error testing until the number of effective nodes for further use was obtained, by the selection of models with the highest accuracy $[27,28]$. 


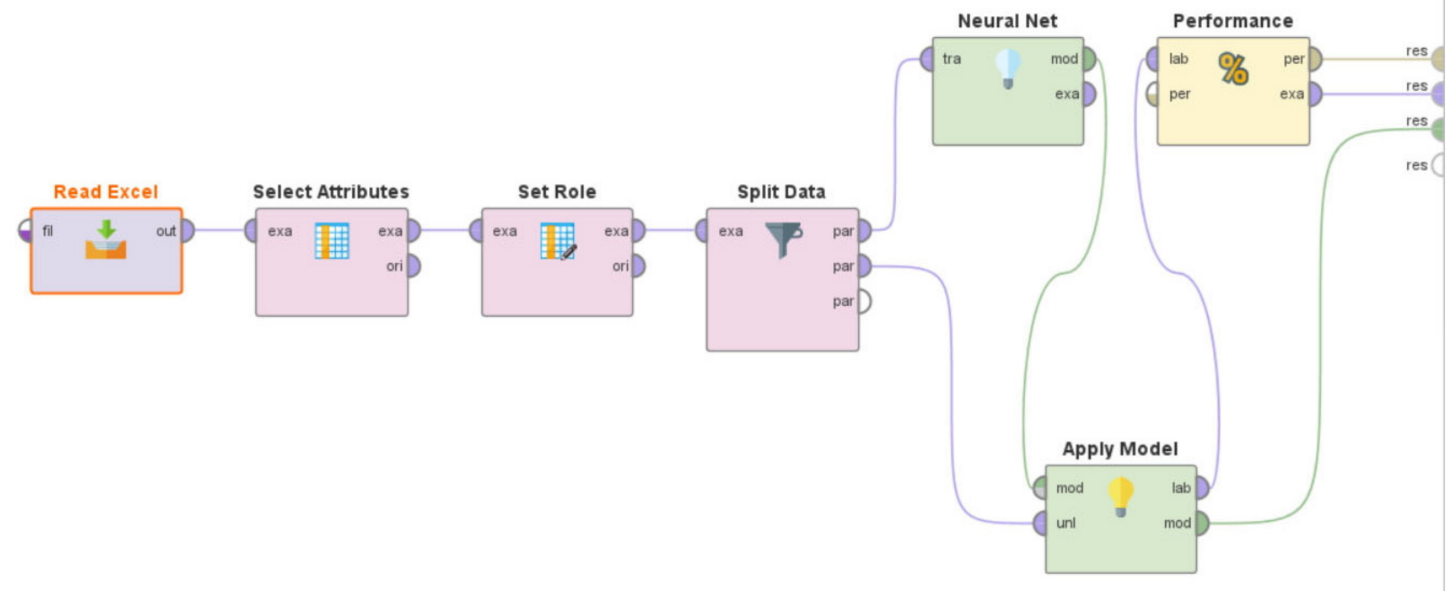

Figure 13. Processes used to create ANN landslide forecasting models via RapidMiner.

\section{Results}

For the estimation of the landslide risk in this study, data were collected to be used as modeling factors and node quantification tests were carried out to retrieve the most suitable model for estimating the risk of landslides. The results of the modeling are discussed in the next section.

\subsection{Modeling}

The 9602 data points collected were used to create a landslide risk model via the ANN approach. To achieve the best models, a number of node tests had to be performed, starting with the rules of thumb in which the data used had a total of eight independent variables. When performing trial-and-error tests for the number of nodes and layers, which may result in a greater accuracy than when using rules of thumb, a ROC curve indicating the accuracy of the model resulted, as shown in Figure 14.

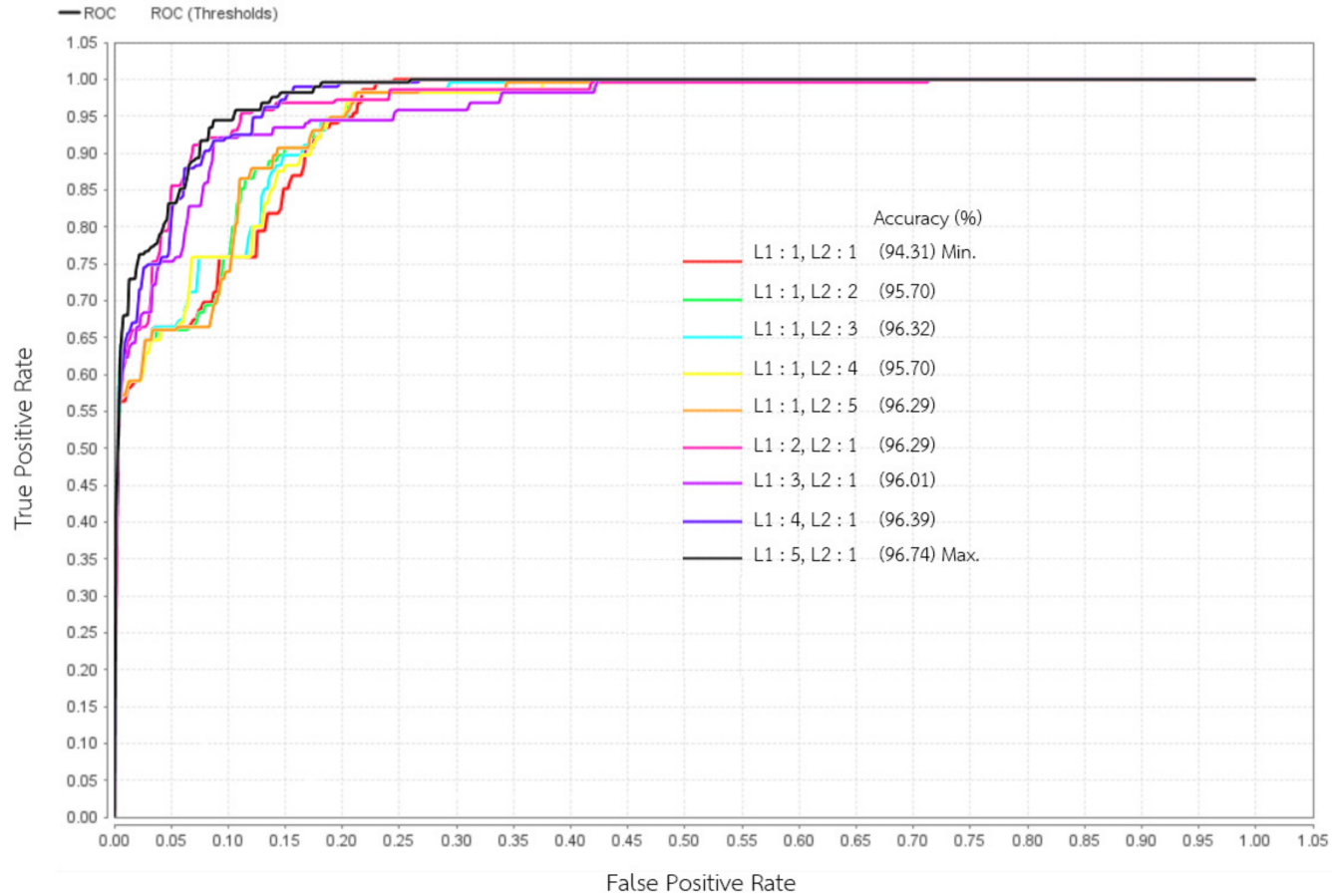

Figure 14. ROC curve from trial-and-error testing. 
Figure 14 presents the top nine values of ROC curves, selected to convey the trend of ROC curves from 25 trial-and-error tests. The appropriate number of nodes retrieved from the trial-and-error tests in the first and next hidden layer was five and one, respectively. During testing, this number of nodes achieved the highest accuracy value of $96.74 \%$; the resulting ANN architecture is presented in Figure 15.

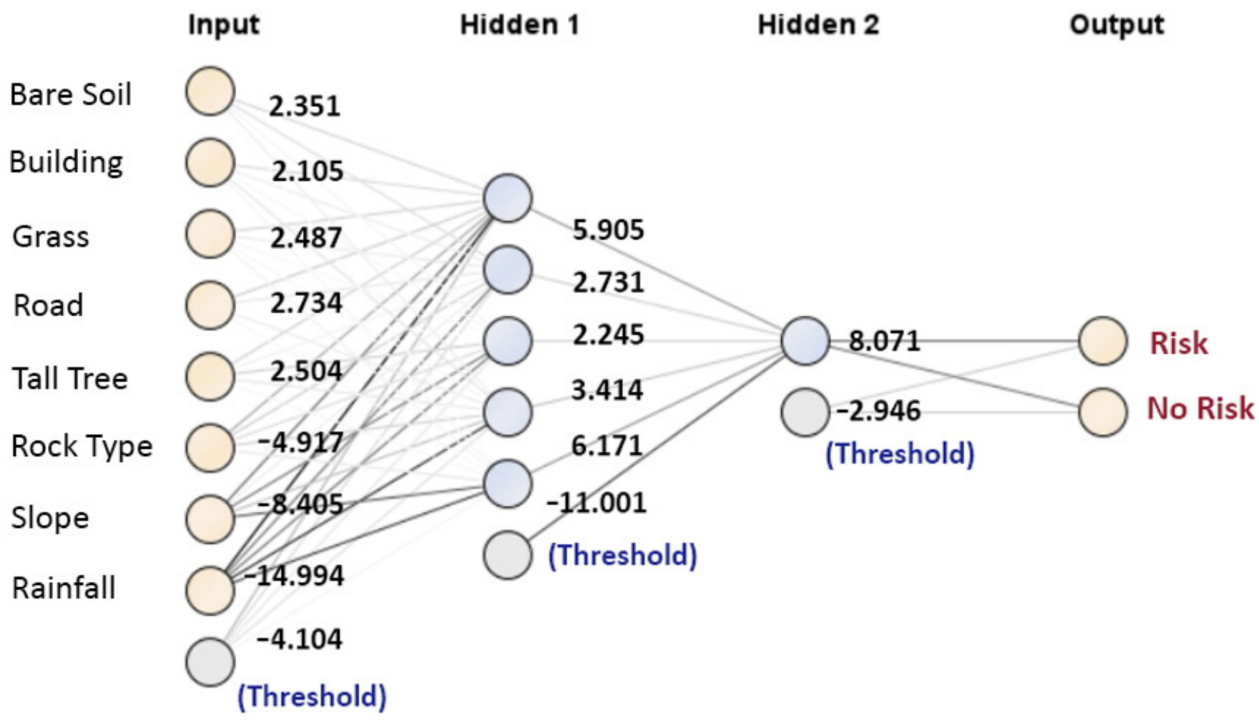

Figure 15. ANN architecture displayed in RapidMiner.

Once the appropriate number of nodes was obtained, the model could be applied to estimate the risk of landslides by preparing a new set of data, in which the focus was on the key variables, namely, land cover, road types, slope angles, and rainfall data.

\subsection{Application}

The study focused on roadside areas and considered the physiographic data, which showed that most areas had metamorphic and sedimentary rocks. Therefore, the application of the model was initiated in the case of roadside areas only if the physiographic type was metamorphic and sedimentary rocks. Applying the landslide risk model using an ANN for analysis in the last step, a graph displaying the relationship between the risk of landslides, rainfall, and slope angle in road areas was drawn, as shown in Figure 16.

In Figure 16, the $x$-axis is the cumulative rainfall over five days in the range of $0-100 \mathrm{~mm}$, and the $y$-axis is the landslide risk, where 0 is the lowest risk and 1 is the highest risk. The graph is divided into three slope lines: $10^{\circ}, 20^{\circ}$, and $30^{\circ}$. For the first of the three slope lines, with low five-day rainfall accumulation the landslide risk is relatively low, but then it gradually begins to change. The slope lines at $20^{\circ}$ and $30^{\circ}$ begin to change when the accumulated rainfall for five days reaches $30 \mathrm{~mm}$. In addition, the slope line at $10^{\circ}$ changes when the cumulative rainfall for five days reaches $40 \mathrm{~mm}$. The rate of change has an $S$ shape, leveling out when the five-day cumulative rainfall equals $50 \mathrm{~mm}$, where all three slope lines are approximately equal.

However, analyzing the graphs further, it can be seen that slopes of $20^{\circ}$ and higher are clearly different from the slope of $10^{\circ}$ at the point at which the landslide risk reaches 0.50. Additionally, there are no differences between the graphs for slopes of $20^{\circ}$ and $30^{\circ}$, and their graphs meet that of a $10^{\circ}$ slope when the likelihood of risk is 0.85 . Considering a landslide risk with a value greater than 0.50 (threshold) to be high, the cumulative rainfall for five days, consequently, is $38 \mathrm{~mm}$ for slopes of $20^{\circ}$ and $30^{\circ}$. On the other hand, when a landslide risk of 0.85 (threshold) is considered to be high, when the five-day cumulative rainfall equals $50 \mathrm{~mm}$ all slopes can be defined as at high risk of landslides, depending on how sensitive the area is. Nonetheless, when the five-day cumulative rainfall is equal to 
$50 \mathrm{~mm}$, based on this graph, this is considered an important point to monitor for further planning purposes.

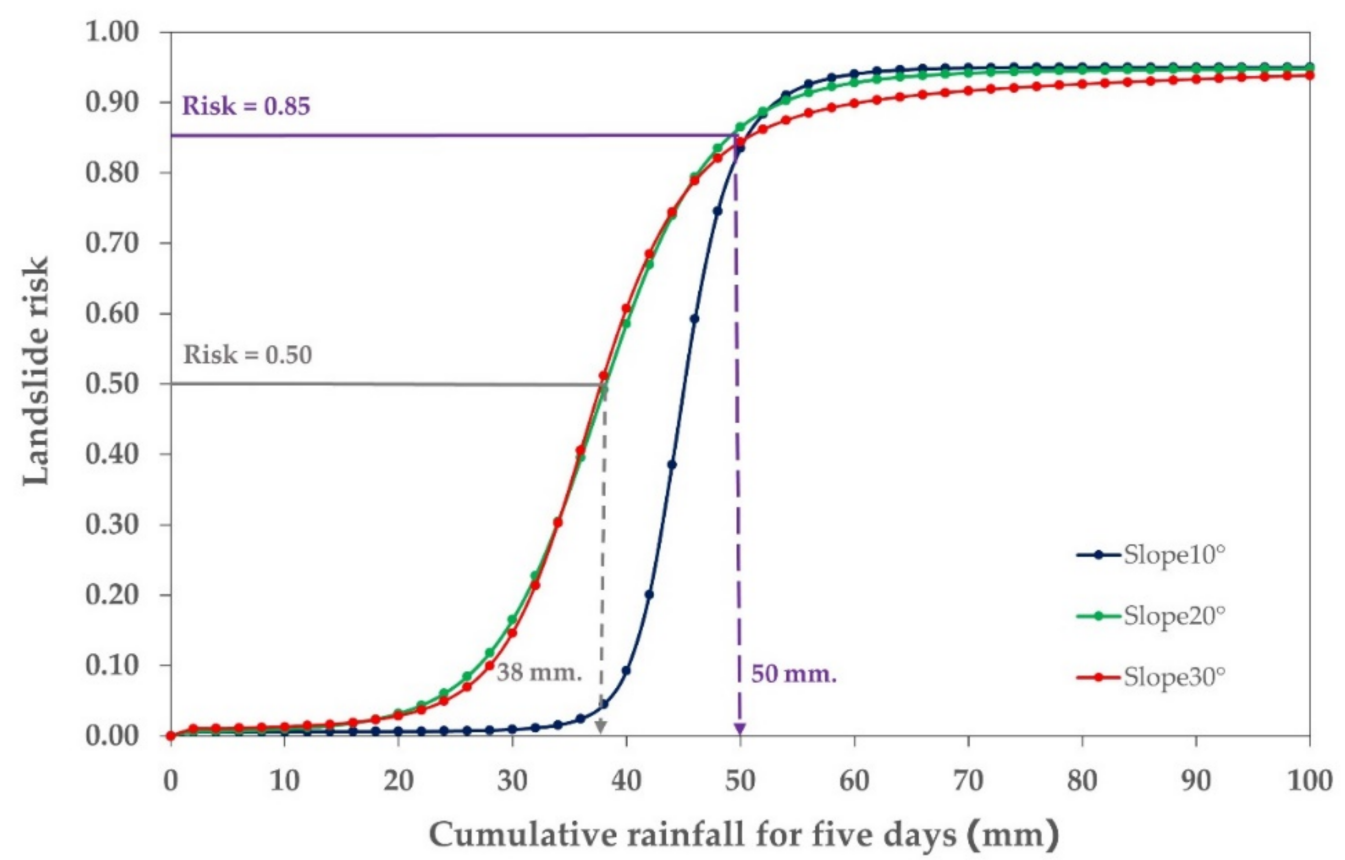

Figure 16. Relationship between landslide risk, rainfall, and slope in road areas.

\section{Discussion and Conclusions}

As a result of repeatedly occurring landslide incidents near roads in the upper north of Thailand, damage has greatly affected traffic and, at times, roadside construction also. Therefore, to mitigate the damaging impact, in this study we assessed the risk of landslides using an ANN technique that creates forecasting models in RapidMiner. Field data were collected, in addition to information obtained from relevant departments, together with all the data from past landslides in the study areas of Chiang Rai and Chiang Mai Provinces, totaling 9602 data points, consisting of types of land cover, physiographic classifications, slope angles, five-day cumulative rainfall, and landslide risk. The resulting graphs were consistent with literature reviews indicating that the likelihood of landslides increases on slopes of $15^{\circ}-30^{\circ}$ [18]. Moreover, the theories also indicate that steep slopes result in more landslides than low slopes [17], even though our graph at $20^{\circ}$ looks the same as that for $30^{\circ}$. This may be due to the data collected having slopes at $20^{\circ}$ rather than at $30^{\circ}$. It is evident from the data scale that slopes of $30^{\circ}$ and above were very limited compared to slopes of $10^{\circ}$ and $20^{\circ}$, so it is possible that the modeling approaches applied included slope values in the range of $20^{\circ}-30^{\circ}$ in the same group.

Furthermore, the results show that if there was heavy rainfall for five consecutive days within an area with other risk factors, such as a relatively steep slope, the likelihood of landslides was high [23]. Rainfall is the main factor determining landslides [22], which means that for any areas located on a roadside with accumulated rainfall of five or more days, regardless of the slope, when the rainfall increases steadily, the chances of landslides are quite high. Rainfall, as a result, is the major trigger for landslides [21].

This study describes a modeling process for measuring landslide susceptibility using reliable historical data. These processes can be applied to other areas that are at high risk of landslides and need to be assessed for susceptibility. However, appropriate local data should be considered, to improve the model's accuracy and benefit future local landslide studies. However, the estimation of the landslide risk from models created by the ANN method and the application of the findings to create risk maps or for use in monitoring and measurement planning are different from the methods used in the past in Thailand [6,42]. In addition, this study will be helpful in further research, and the estimation of landslide 
risk will also benefit multiple sectors of land use planners, such as local departments or the Rural Roads Department, to design and maintain roads while reducing the road design risks and to plan for construction in areas around roads in mountainous areas in the northern provinces of Thailand while reducing the risk of unforeseen landslide incidents in the future.

Author Contributions: Conceptualization, C.A., P.J., D.R. and N.T.; methodology P.J., D.R. and N.T.; software, W.T., C.D. and S.S.; validation, C.A., P.J., D.R. and N.T.; investigation, S.T. and T.K.N.A.; writing-original draft preparation, C.D., S.S. and D.R.; writing-review and editing, P.J. and D.R.; visualization, C.D. and S.S.; supervision, C.A. and P.J.; project administration, S.M. and D.R.; funding acquisition, C.A. All authors have read and agreed to the published version of the manuscript.

Funding: This research was funded by Thailand Science Research and Innovation (TSRI), Thailand.

Institutional Review Board Statement: Not applicable.

Informed Consent Statement: Not applicable.

Data Availability Statement: The data presented in this study are available on request from the corresponding author.

Acknowledgments: The authors wish to thank supporting staff from the City Research and Development Center, Faculty of Engineering, Chiang Mai University, and the Center of Excellence in Natural Disaster Management (CENDiM), Chiang Mai University, Thailand.

Conflicts of Interest: The authors declare no conflict of interest.

\section{References}

1. Herath, S.; Wang, Y. Case studies and national experiences. In Landslides-Disaster Risk Reduction; Springer: Berlin/Heidelberg, Germany, 2009; pp. 475-497.

2. Kjekstad, O.; Highland, L. Economic and Social Impacts of Landslides. In Landslides-Disaster Risk Reduction; Sassa, K., Canuti, P., Eds.; Springer: Berlin/Heidelberg, Germany, 2009; pp. 573-587.

3. Abraham, M.T.; Satyam, N.; Rosi, A.; Pradhan, B.; Segoni, S. The selection of rain gauges and rainfall parameters in estimating intensity-duration thresholds for landslide occurrence: Case study from Wayanad (India). Water 2020, 12, 1000. [CrossRef]

4. Petpongpan, C.; Ekkawatpanit, C.; Kositgittiwong, D. Landslide risk assessment using hydrological model in the Upper Yom River Basin, Thailand. CATENA 2021, 204, 105402. [CrossRef]

5. Department of Mineral Resources. North and Upper West. 2016. Available online: http://www.dmr.go.th/more_news.php?cid= 191\&filename=index (accessed on 31 October 2021). (In Thai)

6. Tengtrairat, N.; Woo, W.L.; Parathai, P.; Aryupong, C.; Jitsangiam, P.; Rinchumphu, D. Automated Landslide-Risk Prediction Using Web GIS and Machine Learning Models. Sensors 2021, 21, 4620. [CrossRef] [PubMed]

7. Chiang Mai News. Chiang Rai Floods Landslide Hits School Building after Continuous Heavy Rain. Chiang Mai News. 2019. Available online: https: / www.chiangmainews.co.th/page/archives/1098987/ (accessed on 31 October 2021). (In Thai).

8. 7HD Channel. Chiang Rai Flooding and Landslides in Many Areas Relevant Agencies Mobilize to Help the Villagers. 7HD Hot Online. 2021. Available online: https:/ / news.ch7.com/detail/507922 (accessed on 31 October 2021). (In Thai).

9. MGR Online. Put up a Sign for a Landslide Disaster Area. The Way up to Phu Chee Fah. MGR Online. 2018. Available online: https://mgronline.com/local/detail/9610000075917 (accessed on 31 October 2021). (In Thai).

10. Thairath Online. Rain Collapses, Doi Mae Salong Road Collapses 1.5 Meters and Soil Slides over 3 Houses at the Foot of the Hill Collapse. Thai Rath. 2017. Available online: https://www.thairath.co.th/news/local/north/1062644 (accessed on 31 October 2021). (In Thai).

11. Shu, H.; Hürlimann, M.; Molowny-Horas, R.; González, M.; Pinyol, J.; Abancó, C.; Ma, J. Relation between land cover and landslide susceptibility in Val d'Aran, Pyrenees (Spain): Historical aspects, present situation and forward prediction. Sci. Total Environ. 2019, 693, 133557. [CrossRef]

12. Zhao, J.; Zhao, X.; Liang, S.; Zhou, T.; Du, X.; Xu, P.; Wu, D. Assessing the thermal contributions of urban land cover types. Landsc. Urban Plan. 2020, 204, 103927. [CrossRef]

13. Department of Mineral Resources. Knowledge of Landslides (in Thai); Resources, M., Ed.; 2010. Available online: http:/ / www.dmr. go.th/download/Landslide/what_landslide1.htm (accessed on 31 October 2021).

14. Liao, K.-W.; Hoang, N.-D.; Chang, S.-C. Estimating landslide occurrence via small watershed method with relevance vector machine. Earth Sci. Inform. 2020, 13, 249-260. [CrossRef]

15. Marc, O.; Gosset, M.; Saito, H.; Uchida, T.; Malet, J.P. Spatial patterns of storm-induced landslides and their relation to rainfall anomaly maps. Geophys. Res. Lett. 2019, 46, 11167-11177. [CrossRef] 
16. Chen, X.; Liu, C.; Wang, M. A method for quick assessment of earthquake-triggered landslide hazards: A case study of the Mw6.1 2014 Ludian, China earthquake. Bull. Eng. Geol. Environ. 2019, 78, 2449-2458. [CrossRef]

17. Pal, S.C.; Das, B.; Malik, S. Potential Landslide Vulnerability Zonation Using Integrated Analytic Hierarchy Process and GIS Technique of Upper Rangit Catchment Area, West Sikkim, India. J. Indian Soc. Remote Sens. 2019, 47, 1643-1655. [CrossRef]

18. Chen, Z.; Liang, S.; Ke, Y.; Yang, Z.; Zhao, H. Landslide susceptibility assessment using different slope units based on the evidential belief function model. Geocarto Int. 2020, 35, 1641-1664. [CrossRef]

19. Guo, C.-W.; Huang, Y.-D.; Yao, L.-K.; Alradi, H. Size and spatial distribution of landslides induced by the 2015 Gorkha earthquake in the Bhote Koshi river watershed. J. Mt. Sci. 2017, 14, 1938-1950. [CrossRef]

20. Yang, Z.; Li, X.; Zhao, Q.; Zhang, Y.; Liu, X. Key Influencing factors based distribution regularity and deformation and failure response of colluvial landslides in three gorges reservoir area. J. Eng. Geol. 2021, 29, 617.

21. Chatra, A.S.; Dodagoudar, G.R.; Maji, V.B. Numerical modelling of rainfall effects on the stability of soil slopes. Int. J. Geotech. Eng. 2019, 13, 425-437. [CrossRef]

22. Rakkapao, N.; Plodpai, P.; Boonma, K.; Wimonsong, P. Landslide Risk Assessment using Geographic Information System: A case study of Phanom District, Surat Thani Province, Thailand. J. Spat. Innov. Dev. 2020, 1, 74-82.

23. Dang, K.; Loi, D.H.; Hirota, K.; Taniguchi, Y.; Sassa, K. Landslide triggered by heavy rainfall on 06 September 2020 in Shiiba village, Miyazaki Prefecture, Japan. Landslides 2021, 18, 3485-3488. [CrossRef]

24. Kim, J.; Kim, Y.; Jeong, S.; Hong, M. Rainfall-induced landslides by deficit field matric suction in unsaturated soil slopes. Environ. Earth Sci. 2017, 76, 1-17. [CrossRef]

25. Mandal, S.; Mondal, S. Artificial Neural Network (ANN) Model and Landslide Susceptibility. In Statistical Approaches for Landslide Susceptibility Assessment and Prediction; Mandal, S., Mondal, S., Eds.; Springer International Publishing: Cham, Switzerland, 2019; pp. 123-133.

26. Jacinth Jennifer, J.; Saravanan, S. Artificial neural network and sensitivity analysis in the landslide susceptibility mapping of Idukki district, India. Geocarto Int. 2021, 1-23. [CrossRef]

27. Sadighi, M.; Motamedvaziri, B.; Ahmadi, H.; Moeini, A. Assessing landslide susceptibility using machine learning models: A comparison between ANN, ANFIS, and ANFIS-ICA. Environ. Earth Sci. 2020, 79, 536. [CrossRef]

28. Kalantar, B.; Pradhan, B.; Naghibi, S.A.; Motevalli, A.; Mansor, S. Assessment of the effects of training data selection on the landslide susceptibility mapping: A comparison between support vector machine (SVM), logistic regression (LR) and artificial neural networks (ANN). Geomat. Nat. Hazards Risk 2018, 9, 49-69. [CrossRef]

29. Aditian, A.; Kubota, T.; Shinohara, Y. Comparison of GIS-based landslide susceptibility models using frequency ratio, logistic regression, and artificial neural network in a tertiary region of Ambon, Indonesia. Geomorphology 2018, 318, 101-111. [CrossRef]

30. Yu, C.; Chen, J. Landslide Susceptibility Mapping Using the Slope Unit for Southeastern Helong City, Jilin Province, China: A Comparison of ANN and SVM. Symmetry 2020, 12, 1047. [CrossRef]

31. Bragagnolo, L.; da Silva, R.V.; Grzybowski, J.M.V. Landslide susceptibility mapping with r.landslide: A free open-source GIS-integrated tool based on Artificial Neural Networks. Environ. Model. Softw. 2020, 123, 104565. [CrossRef]

32. Valencia Ortiz, J.A.; Martínez-Graña, A.M. A neural network model applied to landslide susceptibility analysis (Capitanejo, Colombia). Geomat. Nat. Hazards Risk 2018, 9, 1106-1128. [CrossRef]

33. Sevgen, E.; Kocaman, S.; Nefeslioglu, H.A.; Gokceoglu, C. A Novel Performance Assessment Approach Using Photogrammetric Techniques for Landslide Susceptibility Mapping with Logistic Regression, ANN and Random Forest. Sensors 2019, $19,3940$. [CrossRef] [PubMed]

34. Soma, A.S.; Kubota, T.; Mizuno, H. Optimization of causative factors using logistic regression and artificial neural network models for landslide susceptibility assessment in Ujung Loe Watershed, South Sulawesi Indonesia. J. Mt. Sci. 2019, 16, 383-401. [CrossRef]

35. Nhu, V.-H.; Shirzadi, A.; Shahabi, H.; Singh, S.K.; Al-Ansari, N.; Clague, J.J.; Jaafari, A.; Chen, W.; Miraki, S.; Dou, J.; et al. Shallow Landslide Susceptibility Mapping: A Comparison between Logistic Model Tree, Logistic Regression, Naïve Bayes Tree, Artificial Neural Network, and Support Vector Machine Algorithms. Int. J. Environ. Res. Public Health 2020, 17, 2749. [CrossRef]

36. Kuradusenge, M.; Kumaran, S.; Zennaro, M. Rainfall-Induced Landslide Prediction Using Machine Learning Models: The Case of Ngororero District, Rwanda. Int. J. Environ. Res. Public Health 2020, 17, 4147. [CrossRef]

37. Chen, W.; Yan, X.; Zhao, Z.; Hong, H.; Bui, D.T.; Pradhan, B. Spatial prediction of landslide susceptibility using data mining-based kernel logistic regression, naive Bayes and RBFNetwork models for the Long County area (China). Bull. Eng. Geol. Environ. 2019, 78, 247-266. [CrossRef]

38. Yadav, A.K.; Malik, H.; Chandel, S.S. Application of rapid miner in ANN based prediction of solar radiation for assessment of solar energy resource potential of 76 sites in Northwestern India. Renew. Sustain. Energy Rev. 2015, 52, 1093-1106. [CrossRef]

39. László, K.; Ghous, H. Efficiency comparison of Python and RapidMiner. Multidiszcip. Tudományok 2020, 10, $212-220$.

40. Sitthikankun, S.; Rinchumphu, D.; Buachart, C.; Pacharawongsakda, E. Construction cost estimation for government building using Artificial Neural Network. Int. Trans. J. Eng. Manag. Appl. Sci. Technol. 2021, 12, 1-12.

41. Celik, U.; Basarir, C. The Prediction of Precious Metal Prices via Artificial Neural Network by Using RapidMiner. Alphanumeric J. 2017, 5, 45. [CrossRef] 
42. Department of Mineral Resources. Project to Provide Information on Landslide Risk Areas at Community Level, Chokchai Subdistrict, Doi Luang District, Chiang Rai Province. 2013. Available online: http://www.dmr.go.th/download/Landslide/ community (accessed on 31 October 2021). (In Thai)

43. Department of Mineral Resources. Project to Provide Information on Landslide Risk Areas at Community Level, Ban Pong Subdistrict, Phrao District, Chiang Mai Province. 2013. Available online: http://27.254.88.57/download/Landslide/community (accessed on 31 October 2021). (In Thai)

44. Ranjan, C. Rules-of-Thumb for Building a Neural Network. Available online: https://towardsdatascience.com/17-rules-ofthumb-for-building-a-neural-network-93356f9930af (accessed on 13 April 2021). 